\title{
Acute exacerbation of COPD during pulmonary rehabilitation: outcomes and risk prediction
}

This article was published in the following Dove Press journal:

International Journal of COPD

\author{
Bertrand Herer' \\ Thierry Chinet ${ }^{2}$ \\ 'Pulmonary Rehabilitation Unit, \\ Pulmonary Department, Centre \\ Hospitalier De Bligny, Briis sous \\ Forges, France; ${ }^{2}$ Pneumology \\ Unit, Hôpital A. Paré, Boulogne- \\ Billancourt, France
}

\begin{abstract}
Purpose: This study was performed to examine acute exacerbation of COPD (AECOPD) during pulmonary rehabilitation (PR) and the usefulness of multidimensional indices (MIs) to predict AECOPD at enrolment in PR.

Patients and methods: A 4-week PR program (PRP) was implemented for 125 consecutive patients with COPD. At baseline and PRP completion, we recorded the $\mathrm{FEV}_{1}, 6$-minute walk test, peak work rate at cardiopulmonary testing, modified Medical Research Council score, and COPD Assessment Test (CAT) score. The risk of AECOPDs at baseline was assessed using the body mass index, airway obstruction, dyspnea, Exercise capacity (BODE), dyspnea, obstruction, smoking, exacerbation (DOSE), and score to predict short-term risk of COPD exacerbations (SCOPEX) MIs.

Results: Thirty-two episodes of AECOPD occurred. The COPD status was worse in patients with than without AECOPD at baseline (lower $\mathrm{FEV}_{1}, 6$-minute walk test, and peak work rate; higher modified Medical Research Council and CAT scores). The sensitivities of the BODE, DOSE, and SCOPEX MIs to predict the occurrence of AECOPD during PRP were $78.1 \%$, $21.9 \%$, and $84.4 \%$, and the specificities were $73.6 \%, 87.1 \%$, and $51.6 \%$, respectively.

Conclusion: The BODE and SCOPEX MIs help to predict the exacerbation risk during PR. Keywords: COPD, rehabilitation, exacerbation, multidimensional indices
\end{abstract}

\section{Introduction}

Pulmonary rehabilitation (PR) is recommended for symptomatic patients with COPD. ${ }^{1}$ "Frequent exacerbators" more commonly exhibit physical inactivity, which in turn contributes to increased susceptibility to new exacerbations. ${ }^{2}$ The most appropriate time point at which to enroll patients with COPD in a PR program (PRP) according to the acute illness experienced during acute exacerbation of COPD (AECOPD) is controversial. Some authors recommend beginning a PRP shortly after inpatient hospitalization for AECOPD, but it has more recently been suggested that enrolling a patient too soon in a PRP process may be beyond the patients' capabilities and even be deleterious. ${ }^{3,4}$ The occurrence of an AECOPD during a PRP may compromise the outcomes of the program or result in the patient dropping out or not attending the PRP. ${ }^{5-7}$ However, in a large population of severely impaired patients with COPD characterized by high rates of AECOPD, a comprehensive PRP induced a significant reduction in exacerbations and hospitalizations up to 1 year after the program. ${ }^{8}$ Few trials have specifically addressed the impact of AECOPD during a PRP on the attendance and outcomes of the PRP. ${ }^{9,10}$ Several multidimensional indices (MIs) of COPD severity have been developed and found useful in the prediction of the risk of AECOPD. ${ }^{11}$ The body mass index, airway obstruction, dyspnea, exercise capacity (BODE) index was first proposed as a predictor of the risk of death among patients with $\mathrm{COPD}^{12}$ and was
Correspondence: Bertrand Herer Pulmonary Rehabilitation Unit, Pulmonary Department, Centre Hospitalier De Bligny, Briis sous Forges 91640 , France $\mathrm{Tel}+33169263743$

Fax +33169263744

Email b.herer@chbligny.fr
International Journal of COPD 20|8:13 |767-1774 
later shown to be a good predictor of the number and severity of exacerbations in these patients. ${ }^{13}$ Jones et al showed that the dyspnea, obstruction, smoking, exacerbation (DOSE) index is a useful tool for assessing the severity of COPD ${ }^{14}$ and later found that it was a good predictor of AECOPD in the first year after its determination. ${ }^{15}$ More recently, the score to predict short-term risk of COPD exacerbations (SCOPEX) has been proposed for short-term (6-month) prediction of AECOPD, but as stated by the authors, this score was based on data from patients enrolled in clinical trials and should be examined in a real-world population of patients with COPD in clinical practice. ${ }^{16}$ However, the specific support that these indices may offer in predicting AECOPD during the course of a PRP is not known.

The aims of this study were therefore to 1) describe the occurrence of AECOPD episodes during realization of a comprehensive PRP, 2) determine the impact of AECOPD on PR outcomes, and 3) study the usefulness of three MIs (BODE, DOSE, and SCOPEX) in predicting AECOPD during the course of a PRP.

\section{Patients and methods}

\section{Study design and participants}

We conducted a prospective observational study of patients with COPD successively enrolled in a comprehensive PRP at the Bligny Hospital Center. All patients participated in the PRP, either as inpatients (ie, conventional hospitalization sector) or outpatients from February 2015 to January 2017. The referral criteria were a diagnosis of COPD (smoking history of $\geq 10$ pack-years and a post-bronchodilator $\mathrm{FEV}_{1} /$ FVC ratio of $<0.7$ ) and diminished physical performance related to COPD. The exclusion criteria were uncontrolled comorbidities or physical inability to exercise, impairment of cognition or communication, and a lack of motivation to participate in the PRP. All patients gave written informed consent for inclusion in the PRP, and the study was approved by the Institutional Review Board of the French Society for Respiratory Medicine (Société de Pneumologie de Langue Française, CEPRO 2016-030).

\section{PRP}

All patients underwent an individually tailored comprehensive PRP of 4 weeks' duration carried out by groups of seven persons. The patients participated 5 days a week for an average of 30 hours per week. The PRP comprised the following: 1) exercise sessions, including determination of cycle exercise endurance at a constant work rate beginning at $\sim 75 \%$ of the peak work rate (WR peak) obtained during incremental tests performed at initiation of the PRP, and strength training, including progressive resistance exercises with hand weights, elastic resistance tubing, and weight machines; 2) an educational component that included instruction and participation in workshops on the topics of pulmonary disease comprehension; therapeutic, nutritional, and exercise issues; and self-management strategies against COPD exacerbations; and 3) workshops helping the patients to desensitize to dyspnea, organized as group sessions and including sophrology, speech therapy with actors, and singing therapy with musicians. ${ }^{17}$ In addition to the group sessions, patients received interventions on an individual basis (counseling with a psychologist and/or social worker and smoking cessation management when needed). The medical treatments being used by patients at baseline were recorded and not modified during the PRP.

\section{Measurements}

The following demographic data were recorded at initiation of the PRP: age, sex, distance from the hospital, smoking status, and regular use of oxygen. The Charlson comorbidity index was calculated. ${ }^{18} \mathrm{COPD}$ was classified according to the severity of airflow limitation (Global Initiative for Chronic Obstructive Lung Disease [GOLD] stages 1-4) and based on symptoms, breathlessness, spirometric classification, and risk of exacerbations (GOLD stages A-D). ${ }^{19}$

The following measurements were obtained at baseline and at PRP completion: body mass index (BMI), spirometry results $\left(\mathrm{FVC}, \mathrm{FEV}_{1}\right.$, and $\mathrm{FEV}_{1} / \mathrm{FVC}$ ), 6-minute walk test (6MWT), and cardiopulmonary exercise testing with calculation of peak oxygen uptake $\left(\mathrm{VO}_{2}\right.$ peak) and WR peak. We used the following self-administered questionnaires to record the clinical impact of COPD and the health status of the patients: the modified Medical Research Council (mMRC) scale, graded from 0 to 4 , was used to quantify the dyspnea; ${ }^{20}$ the Hospital Anxiety and Depression Scale (HADS) was used to evaluate the patients' anxiety and depression status; ${ }^{21}$ and the previously validated French versions of the COPD Assessment Test (CAT) ${ }^{22}$ and the Visual Simplified Respiratory Questionnaire (VSRQ) ${ }^{23}$ were used to assess the overall health status. The minimal clinically important difference was used to characterize which patients benefited from PR and was defined using the following thresholds according to the published literature: $a \geq 30-m$ increase in the $6 \mathrm{MWT},{ }^{24} \mathrm{a} \geq 1$-unit decrease in the mMRC score, ${ }^{25} \mathrm{a}>1.5$-unit decrease in the HADS score, ${ }^{26} \mathrm{a}>2$-unit decrease in the CAT score, ${ }^{27} \mathrm{a}>3.5$-unit increase in the VSRQ score, ${ }^{23}$ and $\mathrm{a} \geq 5-\mathrm{W}$ increase in the WR peak. ${ }^{28}$ 


\section{COPD exacerbations and prediction of short-term risk of exacerbations by Mls}

The number of AECOPD episodes in the year preceding enrolment (NEXA) was recorded for each patient. During the PRP, an AECOPD was defined as worsening of two major symptoms (dyspnea and sputum purulence or volume) or one major and one minor symptom (wheeze, asthenia, nasal secretion, sore throat, or cough) for at least 2 consecutive days. ${ }^{29}$ Patients were asked to report any modifications of their symptoms at the beginning of each day during the PRP, and the following information was recorded for each AECOPD episode: the number of days between enrolment in the PRP and the occurrence of AECOPD; the duration of the medical intervention; the sputum culture result; the use of oral corticosteroids and/or antibiotics; and the severity of the event, based on the following criteria adapted from Pavord et al mild event (requiring physiotherapy and/or increased use of a short-acting bronchodilator), moderate event (requiring treatment with an oral corticosteroid and/or antibiotics), or severe event (requiring prolongation of hospitalization or transfer to the intensive care unit)..$^{30}$ The following three MIs were recorded to study their usefulness in predicting the occurrence of an AECOPD during the PRP: the BODE index was calculated at baseline and at the completion of the PRP because of its usefulness in assessing the benefit of $\mathrm{PR},{ }^{31}$ and the DOSE and the SCOPEX indices were calculated at baseline. ${ }^{14,16}$

\section{Outcome measures}

The primary objectives of the study were to determine the proportion of patients who developed an AECOPD during the PRP and describe the characteristics of these episodes. The secondary outcomes were to determine 1) the characteristics of these patients and the impact of the exacerbations on PRP outcomes and 2) the usefulness of the three aforementioned MIs in predicting the short-term (4-week) risk of AECOPD at enrolment in the PRP.

\section{Statistical analysis}

Quantitative data are expressed as mean \pm SD unless otherwise indicated. Categorical data are expressed as number (percentage). Differences in baseline characteristics and analysis of outcomes of PR were compared using repeatedmeasures analysis of variance. Chi-square statistics were used for categorical variables. The NEXA and BODE, DOSE, and SCOPEX indices were compared using receiver operating characteristic (ROC) curves. The area under the ROC curve (AUC) was calculated and ranged from 0 to 1 , with 1 indicating perfect discrimination and $>0.5$ indicating a chance of discrimination. The DeLong method was used for pairwise comparisons of ROC curves. ${ }^{32}$ All factors with a $P$-value $<0.10$ following a univariate analysis were included in a multivariate analysis. Variables used to calculate the BODE, DOSE, and SCOPEX indices were excluded. Statistical significance was set at $P=0.05$. Statistical analysis was performed by MedCalc software, version 12.7.7 (MedCalc Software bvba, Ostend, Belgium).

\section{Results}

\section{Baseline characteristics}

During the study period, 125 patients were enrolled in the PRP. The baseline characteristics of the patients at the time of initial admission are shown in Table 1. The following characteristics were significantly higher in inpatients $(\mathrm{n}=90$, $78 \%)$ compared with outpatients $(n=35,28 \%)$ : distance from the hospital $(\mathrm{km}, 31.0 \pm 20.2$ vs $18.6 \pm 12.6, P=0.001)$, BODE index ( $4.2 \pm 2.3 \pm 2.1$ vs $3.2 \pm 2.1, P=0.02)$, HADS score (16.1 \pm 6.8 vs $13.3 \pm 4.4, P=0.031)$, and CAT score $(21.2 \pm 6.0$ vs $18.2 \pm 7.2, P=0.02)$; the following characteristics were significantly lower in inpatients compared with outpatients: 6MWT (m, 343 \pm 98 vs $399 \pm 79, P=0.003$ ), $\mathrm{VO}_{2}$ peak $(\mathrm{mL} / \mathrm{kg} / \mathrm{min}, 12.4 \pm 3.6$ vs $14.7 \pm 3.9, P=0.005)$, and $W R$ peak (W, $54.6 \pm 21.2$ vs $70.7 \pm 29.7, P=0.002$ ). Figure 1 shows the flowchart of the patients. Thirty-two exacerbations occurred (25.6\% of the patients enrolled in the PRP), affecting 33.3\% of the inpatients and $5.7 \%$ of the outpatients $(P=0.0032)$. Patients in whom an AECOPD occurred (EX group) had a worse COPD status than those in whom no AECOPD occurred (NEX group); the EX group exhibited more frequent regular use of oxygen $(P=0.0001)$, lower $\mathrm{FEV}_{1}(P=0.033)$, lower BODE index $(P<0.001)$, lower BMI $(P=0.003)$, lower 6MWT $(P=0.001)$, lower WR peak $(P<0.001)$, higher mMRC score $(P<0.001)$, and higher CAT score $(P=0.03$; Table 1). Eight patients failed to complete the PRP because of occurrence of AECOPD ( $n=5)$, occurrence of an acute disease during the PRP (cardiovascular event, $\mathrm{n}=1$; pulmonary embolism, $n=1)$, or lack of interest ( $n=1)$.

\section{Response to PR}

The outcomes of PR in all completed stages in the EX and NEX groups $(n=117)$ are shown in Table 2. In general, the occurrence of an AECOPD did not prevent significant improvements in physical functioning, dyspnea, and quality of life, although these improvements occurred to a lesser degree than when AECOPD did not occur. The following rates of improvement in the minimal clinically important 
Table I Baseline characteristics of 125 patients at the beginning of the PRP

\begin{tabular}{|c|c|c|c|}
\hline Subject characteristics & $\begin{array}{l}\text { EX group } \\
(n=32)\end{array}$ & $\begin{array}{l}\text { NEX group } \\
(n=93)\end{array}$ & $P$-value \\
\hline Stages completed & $27 / 32(84.4)$ & $90 / 93(96.8)$ & 0.01 \\
\hline Age, years & $66.4 \pm 7.3$ & $64.5 \pm 8.7$ & 0.26 \\
\hline Sex: male/female & $14 / 18$ & $57 / 36$ & 0.09 \\
\hline Current smoking & $10 / 22(31.3)$ & I8/75 (19.4) & 0.17 \\
\hline Regular use of oxygen & $21 / 11(65.6)$ & $24 / 69(25.8)$ & 0.0001 \\
\hline Charlson score & $4.2 \pm 2.2$ & $3.8 \pm 1.6$ & 0.23 \\
\hline \multicolumn{4}{|l|}{ Pulmonary medication use } \\
\hline No medication & $2(6.2)$ & $3(3.2)$ & 0.37 \\
\hline I medication (LABA or LAMA) & $0(0.0)$ & $6(6.5)$ & \\
\hline $\begin{array}{l}2 \text { medications (LABA and } \\
\text { LAMA or LABA and ICS) }\end{array}$ & II (34.4) & $37(39.8)$ & \\
\hline $\begin{array}{l}3 \text { medications (LABA, LAMA, } \\
\text { and ICS) }\end{array}$ & $19(59.4)$ & $47(50.5)$ & \\
\hline FVC, \% pred & $71.8 \pm 21.7$ & $78.0 \pm 23.0$ & 0.19 \\
\hline $\mathrm{FEV}_{1}, \%$ pred & $39.7 \pm 19.6$ & $48.6 \pm 20.3$ & 0.033 \\
\hline $\mathrm{FEV}_{1} / \mathrm{FVC}$ & $41.5 \pm 10.3$ & $50.3 \pm 13.1$ & 0.001 \\
\hline \multicolumn{4}{|c|}{$\begin{array}{l}\text { COPD classification according to the severity of airflow limitation } \\
\text { (GOLD stages I-4) }\end{array}$} \\
\hline 1 & $2(6.9)$ & $9(9.7)$ & 0.01 \\
\hline 2 & $3(9.4)$ & $33(35.5)$ & \\
\hline 3 & $20(62.5)$ & $30(32.3)$ & \\
\hline 4 & $7(2 \mid .2)$ & $21(22.5)$ & \\
\hline \multicolumn{4}{|c|}{$\begin{array}{l}\text { COPD classification according to symptoms, breathlessness, spirometric } \\
\text { classification, and risk of exacerbations (GOLD stages A-D) }\end{array}$} \\
\hline A & $0(0.0)$ & $\mathrm{I}(\mathrm{I} . \mathrm{I})$ & 0.153 \\
\hline B & $4(12.5)$ & $29(31.2)$ & \\
\hline $\mathrm{C}$ & $0(0.0)$ & I (I.I) & \\
\hline$D$ & $28(87.5)$ & $62(66.6)$ & \\
\hline BODE index & $5.6 \pm 2.2$ & $3.4 \pm 2.0$ & $<0.001$ \\
\hline $\mathrm{BMI}, \mathrm{kg} / \mathrm{m}^{2}$ & $22.9 \pm 4.8$ & $26.6 \pm 6.5$ & 0.003 \\
\hline 6MWT, m & $309 \pm 101$ & $376 \pm 88$ & 0.001 \\
\hline $\mathrm{VO}_{2}$ peak, $\mathrm{mL} / \mathrm{kg} / \mathrm{min}$ & $11.7 \pm 3.5$ & $13.4 \pm 3.8$ & 0.06 \\
\hline WR peak, W & $41.6 \pm 17.2$ & $64.0 \pm 24.3$ & $<0.001$ \\
\hline mMRC score & $2.9 \pm 0.8$ & $2.1 \pm 0.9$ & $<0.001$ \\
\hline HADS score & $|5| \pm 6.4$. & $16.0 \pm 6.1$ & 0.53 \\
\hline CAT score & $22.8 \pm 5.5$ & $19.6 \pm 6.6$ & 0.03 \\
\hline VSRQ score & $31.5 \pm 15.2$ & $36.4 \pm 12.8$ & 0.10 \\
\hline
\end{tabular}

Notes: The patients were allocated into two groups according to the occurrence (EX group) or not (NEX group) of a COPD exacerbation. Data are presented as $\mathrm{n}(\%)$ or mean \pm SD except sex, which is presented as $\mathrm{n}$.

Abbreviations: 6MWT, 6-minute walk test; BMI, body mass index; BODE, body mass index, airway obstruction, dyspnea, exercise capacity; CAT, COPD assessment test; GOLD, Global Initiative for Chronic Obstructive Lung Disease; HADS, Hospital Anxiety and Depression Scale; ICS, inhaled corticosteroid; LABA, long-acting $\beta_{2}$-agonist; LAMA, long-acting muscarinic antagonist; mMRC, modified Medical Research Council; \% pred, percent predicted; PRP, pulmonary rehabilitation program; $\mathrm{VO}_{2}$ peak, peak oxygen uptake; VSRQ, visual simplified respiratory questionnaire; WR peak, peak work rate.

difference thresholds were observed in the EX versus NEX groups, respectively: $\mathrm{a} \geq 30-\mathrm{m}$ in the $6 \mathrm{MWT}$ ( $51.7 \%$ vs $78.9 \%, P=0.0047), a \geq 1$-unit decrease in the mMRC score (66.7\% vs $49.5 \%, P=0.18)$, a $>1.5$-unit decrease in the HADS score ( $69.6 \%$ vs $64.7 \%, P=0.66)$, a $>2$-unit decrease in the CAT ( $46.2 \%$ vs $57.7 \%, P=0.30)$, a $>3.5$-unit increase in the
VSRQ score ( $52.0 \%$ vs $64.4 \%, P=0.26)$, and a $>5$-W increase in the WR peak ( $76.9 \%$ vs $73.5 \%, P=0.73)$.

\section{Prediction of exacerbations}

The characteristics of the 32 AECOPD episodes that occurred in the EX group are shown in Table 3. At baseline, NEXA was significantly higher in the EX group than in the NEX group ( $1.8 \pm 1.7$ vs $1.0 \pm 1.4$ episodes, $P=0.013$ ). Univariate analysis showed that the following factors were significantly associated with the primary outcome: regular use of oxygen $(P<0.0001)$, BODE index $(P<0.0001)$, WR peak $(P<0.0001)$, CAT score $(P=0.02)$, and SCOPEX index $(P<0.0001)$. The multivariate analysis showed that only the BODE index was significantly associated with the primary outcome (hazard ratio, 2.07 [1.23-3.75]; $P<0.0001$ ). The sensitivity, specificity, optimal threshold, and AUC for the BODE, DOSE, and SCOPEX indices and NEXA are shown in Table 4, and the corresponding ROC curves are shown in Figure 2. The pairwise comparison of ROC curves showed significant differences between the AUCs of the BODE and SCOPEX indices and that of the DOSE index $(P=0.0003$ for BODE vs DOSE indices and $P=0.001$ for SCOPEX vs DOSE indices) and NEXA ( $P=0.03$ for BODE index vs NEXA and $P=0.009$ for SCOPEX index vs NEXA). There were no significant differences between the AUCs of the BODE and SCOPEX indices $(P=0.50)$ or the DOSE index and NEXA $(P=0.12)$.

\section{Discussion}

This study has shown that AECOPD during a PRP is not a rare event, especially in patients with more severe COPD, and that such AECOPD episodes should be promptly managed (in $<2$ consecutive days), because patients with exacerbations during a PRP may still complete the PRP and exhibit improved outcomes. Calculation of the BODE and SCOPEX indices at enrolment may help to predict patients at shortterm risk of AECOPD.

Sparse data are available concerning the impact of AECOPD on PR outcomes. Steele et al found that during an 8-week outpatient PRP, 20.5\% of 146 patients experienced an AECOPD and 6.8\% quit the program for that reason. ${ }^{9}$ Marino et al reported that an AECOPD occurred in the first 3 months of management of patients with COPD undergoing physical therapy in 4 (7.8\%) of the 51 patients studied. ${ }^{10}$ Bjoernshave et al performed a study of patients who dropped out of PR because of AECOPD. ${ }^{7}$ They observed PR dropout due to a documented AECOPD in 21 (1.4\%) of 1,538 patients included in a PRP. ${ }^{7}$ 


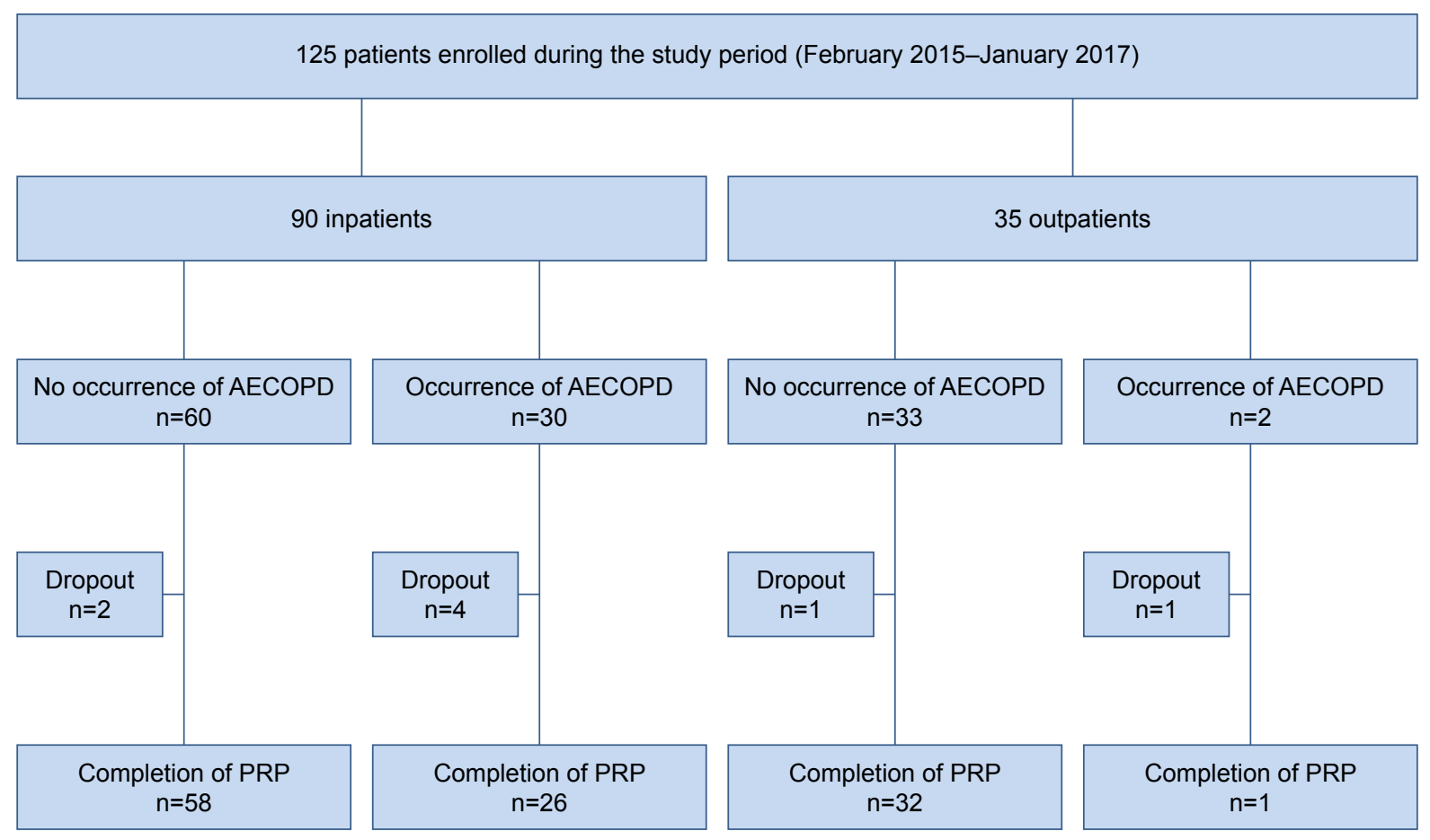

Figure I Flowchart of patients who were enrolled in the study.

Abbreviations: AECOPD, acute exacerbation of COPD; PRP, pulmonary rehabilitation program.

The present study has shown that if the clinical situation of a patient in whom an AECOPD occurs allows manageable therapeutic intervention during PR, significant improvement from this procedure may be obtained, although exacerbators had a worse COPD status than nonexacerbators. The baseline BODE index of patients with AECOPD was higher than that of nonexacerbators $(5.6 \pm 2.2$ vs $3.4 \pm 2.0, P<0.001)$.
The COPD status of exacerbators was also worse in the study performed by Steele et al. ${ }^{9}$ Indeed, this finding is not surprising because it is likely that more rapid health deterioration occurs in patients with frequent $\mathrm{AECOPD}$, while a high rate of AECOPD is a prime reason to enroll a patient in a PRP, as reported by van Ranst et al. ${ }^{8}$ Altenburg et al also stated that patients with a severe COPD status (lower $\mathrm{FEV}_{1}$ and

Table 2 Outcomes of PR in 117 completed stages according to the occurrence (EX group) or nonoccurrence (NEX group) of a COPD exacerbation

\begin{tabular}{|c|c|c|c|c|c|c|c|}
\hline \multirow[t]{2}{*}{ Variable } & \multicolumn{2}{|c|}{ EX group $(n=27)$} & \multicolumn{2}{|c|}{ NEX group $(n=90)$} & \multicolumn{3}{|l|}{$P$-value } \\
\hline & Before PR & After PR & Before PR & After PR & $\begin{array}{l}\text { Between patients } \\
\text { (grouping variable: } \\
\text { exacerbation) }\end{array}$ & $\begin{array}{l}\text { Within patients } \\
\text { (repeated } \\
\text { measure) }\end{array}$ & $\begin{array}{l}\text { Interaction } \\
\text { of factors }\end{array}$ \\
\hline BODE index & $5.4 \pm 2.3$ & $4.2 \pm 1.9$ & $3.3 \pm 1.9$ & $2.3 \pm 1.8$ & $<0.001$ & $<0.001$ & 0.460 \\
\hline FVC, \% pred & $75.2 \pm 19.1$ & $74.1 \pm 17.9$ & $78.8 \pm 22.6$ & $81.9 \pm 22.6$ & 0.246 & 0.499 & 0.048 \\
\hline $\mathrm{FEV}_{1}$, \% pred & $41.9 \pm 19.9$ & $41.2 \pm 18.7$ & $49.0 \pm 20.1$ & $51.0 \pm 21.2$ & 0.068 & 0.696 & 0.064 \\
\hline 6MWT, m & $320 \pm 101$ & $354 \pm 101$ & $379 \pm 85$ & $442 \pm 97$ & $<0.001$ & $<0.001$ & 0.019 \\
\hline $\mathrm{VO}_{2}$ peak, $\mathrm{mL} / \mathrm{kg} / \mathrm{min}$ & $11.9 \pm 3.4$ & $13.6 \pm 4.7$ & $13.5 \pm 3.8$ & $14.8 \pm 5.4$ & 0.421 & 0.013 & 0.860 \\
\hline WR peak, W & $42.1 \pm 17.9$ & $56.7 \pm 20.1$ & $64.0 \pm 23.5$ & $75.4 \pm 28.3$ & 0.001 & $<0.001$ & 0.512 \\
\hline mMRC score & $2.9 \pm 0.8$ & $2.0 \pm 0.9$ & $2.0 \pm 0.9$ & $1.4 \pm 0.8$ & $<0.001$ & $<0.001$ & 0.176 \\
\hline HADS score & $16.0 \pm 6.2$ & $12.6 \pm 5.7$ & $15.0 \pm 6.5$ & $11.3 \pm 6.0$ & 0.305 & $<0.001$ & 0.712 \\
\hline CAT score & $23.0 \pm 5.4$ & $21.0 \pm 6.0$ & $19.6 \pm 6.6$ & $15.4 \pm 6.6$ & $<0.001$ & $<0.001$ & 0.111 \\
\hline VSRQ score & $31.2 \pm 15.4$ & $39.3 \pm 14.8$ & $36.6 \pm 12.7$ & $49.7 \pm 14.2$ & 0.004 & $<0.001$ & 0.093 \\
\hline
\end{tabular}

Note: Data are presented as mean $\pm S D$.

Abbreviations: 6MWT, 6-minute walk test; BODE index, body mass index, airway obstruction, dyspnea, exercise capacity; CAT, COPD Assessment Test; HADS, Hospital Anxiety and Depression Scale; mMRC, modified Medical Research Council; \% pred, percent predicted; PR, pulmonary rehabilitation; VO 2 peak, peak oxygen uptake; VSRQ, visual simplified respiratory questionnaire; WR peak, peak work rate. 
Table 3 Characteristics of 32 AECOPD episodes

\begin{tabular}{ll}
\hline $\begin{array}{l}\text { Occurrence of AECOPD after enrolment } \\
\text { in PRP, days }\end{array}$ & I2.8 $(I 0.1-15.6)^{\mathrm{a}}$ \\
Duration of medical intervention, days & $8.2(6.8-9.5)^{\mathrm{a}}$ \\
Positivity of sputum sample & $9(28.1)^{\mathrm{b}}$ \\
Courses of corticosteroids & $25(78.1)$ \\
Courses of antibiotics & $26(81.3)$ \\
Severity of AECOPD & \\
$\quad$ Mild & $10(31.3)$ \\
Moderate & $16(50.0)$ \\
$\quad$ Severe & $6(18.7)$ \\
\hline
\end{tabular}

Notes: Data are presented as mean $(\mathrm{Cl})$, mean $\pm \mathrm{SD}$, or $\mathrm{n}(\%)$. ${ }^{\mathrm{a}}$ Nonnormal distribution. ${ }^{b}$ Haemophilus influenzae, $n=4$; Staphylococcus aureus, $n=2$; Streptococcus pneumoniae, $\mathrm{n}=\mathrm{I}$; Escherichia coli, $\mathrm{n}=\mathrm{I}$; Pseudomonas aeruginosa, $\mathrm{n}=\mathrm{I}$. 'See definitions in text.

Abbreviations: AECOPD, acute exacerbation of COPD; PRP, pulmonary rehabilitation program.

exercise capacity, more signs of hyperinflation, and worse quadriceps force) may obtain satisfactory outcomes from PR and even improve more in endurance exercise capacity than patients with a less severe COPD status. ${ }^{33}$ van Ranst et al also showed that in a large proportion of severely impaired patients with COPD with high exacerbation rates, those who had more frequent AECOPD episodes before PR had the highest potential for reduction of this event. ${ }^{8}$ More recently, Maddocks et al found that frail patients entering a PRP and demonstrating high levels of impairment when compared with "prefrail" or robust patients had impressive outcomes following PRP completion with better responses in terms of the MRC score, exercise performance, physical activity level, and health status. ${ }^{34}$

These findings indicate that it may be useful to help clinicians to predict the short-term risk of exacerbation before enrolling a patient with COPD in a PRP. The challenge in the present study was to assess the short-term prediction of AECOPD risk using MIs based on readily available clinical features. We chose to assess the BODE, DOSE, and SCOPEX indices for predicting this risk. The BODE index was proposed by Marin et al as a good predictor of the number and severity of AECOPD episodes. ${ }^{13}$ These authors studied a cohort of 245 patients followed every 6 months up to 8 years and found that the BODE index threshold value that was required to observe an AECOPD requiring ambulatory care was 1.9 during a median study period of 5.1 years. ${ }^{13}$ The DOSE index was introduced in 2009 by Jones et al who proposed its use not only as a measure of COPD severity but also as a management tool, including prediction of the number of AECOPD episodes in the subsequent year..$^{14} \mathrm{~A}$ DOSE index of $>4$ was associated with an almost threefold increase in hospital admission, but no threshold value for this index was proposed for prediction of the 1-year risk of AECOPD. More recently, the SCOPEX index was proposed as a predictor of short-term (6-month) prediction of AECOPD by Make et al. ${ }^{16}$ This scoring system has the advantages of being readily available and based on patients' clinical characteristics, while calculation of the BODE index requires availability of the 6MWT. However, no threshold value for a high risk of AECOPD was proposed, and the authors stated that the utility of this index should be examined in a real-world population of patients with COPD in clinical practice. ${ }^{16}$ The use of MIs for prediction of AECOPD is being increasingly studied because composite measures of the impact of COPD account for the diverse dimensions of the disease. A history of exacerbation per se (NEXA in our study) is considered a strong predictor of AECOPD, ${ }^{35}$ but early identification of mild symptoms may be difficult from the patient's and physician's perspective. We found that for the prediction of AECOPD at enrolment in PR, the AUCs of the BODE and SCOPEX indices were significantly larger than those of the DOSE index and NEXA. In addition, the SCOPEX index is easily obtained at the patient's first visit for spirometric confirmation of COPD.

The present study has several limitations. First, it was a single-center study. Second, no significant information could be drawn from the comparison of demographic characteristics between exacerbators who did and did not complete the PRP

Table 4 Sensitivity, specificity, optimal threshold value, and AUC for the BODE, DOSE, SCOPEX indices, and NEXA as predictors of the occurrence of an AECOPD during pulmonary rehabilitation

\begin{tabular}{llllll}
\hline & $\begin{array}{l}\text { Sensitivity } \\
\mathbf{( 9 5 \% ~ C l )}\end{array}$ & $\begin{array}{l}\text { Specificity } \\
\mathbf{( 9 5 \% ~ C l )}\end{array}$ & $\begin{array}{l}\text { Optimal } \\
\text { threshold value }\end{array}$ & AUC (95\% CI) & $P$-value \\
\hline BODE index & $78.1(60.0-90.7)$ & $73.6(64.1-81.7)$ & $>4$ & $0.776(0.692-0.845)$ & $<0.0001$ \\
DOSE index & $21.9(9.3-40.0)$ & $87.1(78.5-93.2)$ & $>4$ & $0.504(0.413-0.594)$ & 0.952 \\
SCOPEX index & $84.4(67.2-94.7)$ & $51.6(41.0-62.1)$ & $>39$ & $0.738(0.652-0.813)$ & $<0.0001$ \\
NEXA & $56.3(37.7-40.0)$ & $66.7(56.1-76.1)$ & $>$ I $)$ & $0.632(0.541-0.717)$ & 0.02 \\
\hline
\end{tabular}

Abbreviations: AECOPD, acute exacerbation of COPD; AUC, area under the receiver operating characteristics curve; BODE, body mass index, airway obstruction, dyspnea, exercise capacity; DOSE, dyspnea, obstruction, smoking, exacerbation; NEXA, number of AECOPD episodes in the year preceding enrolment; SCOPEX, score to predict short-term risk of COPD exacerbations. 


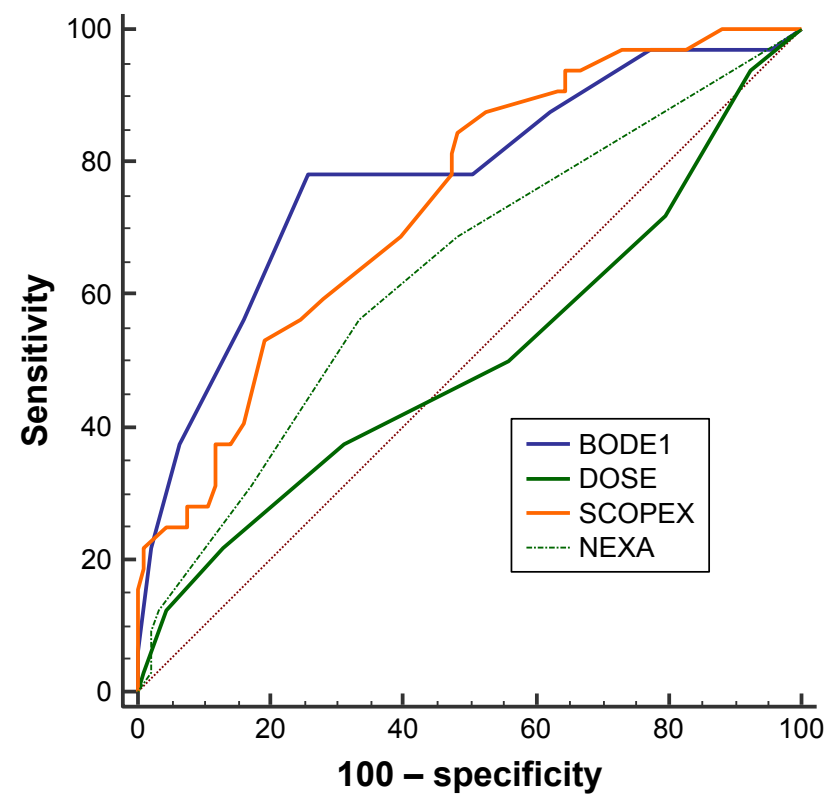

Figure 2 Receiver operating characteristic curves of three multidimensional indices predicting the occurrence of an exacerbation during pulmonary rehabilitation and of NEXA at their optimal threshold value.

Note: Red dotted line: line of identity.

Abbreviations: AECOPD, acute exacerbation of COPD; BODEI, BODE index at baseline; BODE, body mass index, airway obstruction, dyspnea, exercise capacity; DOSE, dyspnea, obstruction, smoking, exacerbation; NEXA, number of AECOPD episodes in the year preceding enrolment; SCOPEX, score to predict short-term risk of COPD exacerbations.

because of the small size of the observed groups and because PRP outcomes were not obtained in cases of PR dropout due to a severe AECOPD. Third, by striving to maintain patients in the PRP with quick management and treatment of AECOPD, we may have increased the emotional distress or anxiety that is frequently associated with $\mathrm{AECOPD}^{36}$ and compromised the patients' ability to absorb the information given in the educational workshops. ${ }^{37}$

\section{Conclusion}

Our results showed that AECOPD during a PRP is not a rare event, especially in patients with more severe COPD. This complication should be promptly managed because these patients may still complete the PRP and exhibit improved outcomes. Calculation of the BODE and SCOPEX indices at enrolment may help to predict patients at short-term risk of AECOPD.

\section{Acknowledgments}

The authors thank Alain Beauchet of the Public Health Department, Unité de Recherche Clinique, Hôpitaux Universitaires Paris Ile-de-France Ouest, Paris, France, for providing statistical assistance. The authors thank the rehabilitation team and Angela Morben, DVM, ELS, from
Edanz Group (www.edanzediting.com/ac) for editing a draft of this manuscript.

\section{Disclosure}

The authors report no conflicts of interest in this work.

\section{References}

1. Puhan MA, Gimeno-Santos E, Cates CJ, Troosters T. Pulmonary rehabilitation following exacerbations of chronic obstructive pulmonary disease. Cochrane Database Syst Rev. 2016;12(1):CD005305.

2. Donaldson GC, Wilkinson TM, Hurst JR, Perera WR, Wedzicha JA. Exacerbations and time spent outdoors in chronic obstructive pulmonary disease. Am J Respir Crit Care Med. 2005;171(5):446-452.

3. Puhan MA, Scharplatz M, Troosters T, Steurer J. Respiratory rehabilitation after acute exacerbation of COPD may reduce risk for readmission and mortality - a systematic review. Respir Res. 2005;6:54.

4. Greening NJ, Williams JE, Hussain SF, et al. An early rehabilitation intervention to enhance recovery during hospital admission for an exacerbation of chronic respiratory disease: randomised controlled trial. BMJ. 2014;349:g4315.

5. Riario-Sforza GG, Incorvaia C, Paterniti F, Dugnani N, Fumagalli M. Different outcomes of pulmonary rehabilitation in patients with COPD with or without exacerbations. Monaldi Arch Chest Dis. 2005;63(3): 129-132.

6. Fischer MJ, Scharloo M, Abbink JJ, et al. Drop-out and attendance in pulmonary rehabilitation: the role of clinical and psychosocial variables. Respir Med. 2009;103(10):1564-1571.

7. Bjoernshave B, Korsgaard J, Nielsen CV. Does pulmonary rehabilitation work in clinical practice? A review on selection and dropout in randomized controlled trials on pulmonary rehabilitation. Clin Epidemiol. 2010;2:73-83.

8. van Ranst D, Stoop WA, Meijer JW, Otten HJ, van de Port IG. Reduction of exacerbation frequency in patients with COPD after participation in a comprehensive pulmonary rehabilitation program. Int J Chron Obstruct Pulmon Dis. 2014;9:1059-1067.

9. Steele BG, Belza B, Cain K, et al. The impact of chronic obstructive pulmonary disease exacerbation on pulmonary rehabilitation participation and functional outcomes. J Cardiopulm Rehabil Prev. 2010; 30(1):53-60.

10. Marino DM, Marrara KT, ArcuriJF, Candolo C, Jamami M, DiLorenzo VA. [Determination of exacerbation predictors in patients with COPD in physical therapy - a longitudinal study]. Braz J Phys Ther. 2014; 18(2):127-136. Portuguese.

11. Motegi T, Jones RC, Ishii T, et al. A comparison of three multidimensional indices of COPD severity as predictors of future exacerbations. Int J Chron Obstruct Pulmon Dis. 2013;8:259-271.

12. Celli BR, Cote CG, Marin JM, et al. The body-mass index, airflow obstruction, dyspnea, and exercise capacity index in chronic obstructive pulmonary disease. N Engl J Med. 2004;350(10):1005-1012.

13. Marin JM, Carrizo SJ, Casanova C, et al. Prediction of risk of COPD exacerbations by the BODE index. Respir Med. 2009;103(3):373-378.

14. Jones RC, Donaldson GC, Chavannes NH, et al. Derivation and validation of a composite index of severity in chronic obstructive pulmonary disease: the DOSE Index. Am J Respir Crit Care Med. 2009;180(12): 1189-1195.

15. Jones RC, Price D, Chavannes NH, et al; UNLOCK Group of the IPCRG. Multi-component assessment of chronic obstructive pulmonary disease: an evaluation of the ADO and DOSE indices and the global obstructive lung disease categories in international primary care data sets. NPJ Prim Care Respir Med. 2016;26:16010.

16. Make BJ, Eriksson G, Calverley PM, et al. A score to predict short-term risk of COPD exacerbations (SCOPEX). Int J Chron Obstruct Pulmon Dis. 2015;10:201-209.

17. Herer B. [Outcomes of a pulmonary rehabilitation program including singing training]. Rev Mal Respir. 2013;30(3):194-202. French. 
18. Charlson M, Szatrowski TP, Peterson J, Gold J. Validation of a combined comorbidity index. J Clin Epidemiol. 1994;47(11):1245-1251.

19. Global Strategy for the Diagnosis, Management and Prevention of COPD, Global Initiative for Chronic Obstructive Lung Disease (GOLD) 2016 [homepage on the Internet]. Available from: http://goldcopd.org/. Accessed December 3, 2017.

20. Han MK, Muellerova H, Curran-Everett D, et al. GOLD 2011 disease severity classification in COPD gene: a prospective cohort study. Lancet Respir Med. 2013;1(1):43-50.

21. Snaith RP. The Hospital Anxiety And Depression Scale. Health Qual Life Outcomes. 2003;1:29.

22. Jones PW, Harding G, Berry P, Wiklund I, Chen WH, Kline Leidy N. Development and first validation of the COPD assessment test. Eur Respir J. 2009;34(3):648-654.

23. Perez T, Arnould B, Grosbois JM, et al. Validity, reliability, and responsiveness of a new short Visual Simplified Respiratory Questionnaire (VSRQ) for health-related quality of life assessment in chronic obstructive pulmonary disease. Int J Chron Obstruct Pulmon Dis. 2009; 4:9-18.

24. Holland AE, Spruit MA, Troosters T, et al. An official European Respiratory Society/American Thoracic Society technical standard: field walking tests in chronic respiratory disease. Eur Respir J. 2014;44(6): $1428-1446$.

25. de Torres JP, Pinto-Plata V, Ingenito E, et al. Power of outcome measurements to detect clinically significant changes in pulmonary rehabilitation of patients with COPD. Chest. 2002;121(4):1092-1098.

26. Bhandari NJ, Jain T, Marolda C, ZuWallack RL. Comprehensive pulmonary rehabilitation results in clinically meaningful improvements in anxiety and depression in patients with chronic obstructive pulmonary disease. J Cardiopulm Rehabil Prev. 2013;33(2):123-127.

27. Kon SS, Canavan JL, Jones SE, et al. Minimum clinically important difference for the COPD assessment test: a prospective analysis. Lancet Respir Med. 2014;2(3):195-203.
28. Puente-Maestu L, Palange P, Casaburi R, et al. Use of exercise testing in the evaluation of interventional efficacy: an official ERS statement. Eur Respir J. 2016;47(2):429-460.

29. Erdal M, Johannessen A, Eagan TM, Bakke P, Gulsvik A, Grønseth R. Incidence of utilization- and symptom-defined COPD exacerbations in hospital- and population-recruited patients. Int J Chron Obstruct Pulmon Dis. 2016;11:2099-2108.

30. Pavord ID, Jones PW, Burgel PR, Rabe KF. Exacerbations of COPD. Int J Chron Obstruct Pulmon Dis. 2016;11 Spec Iss:21-30.

31. Cote CG, Celli BR. Pulmonary rehabilitation and the BODE index in COPD. Eur Respir J. 2005;26(4):630-636.

32. DeLong ER, DeLong DM, Clarke-Pearson DL. Comparing the areas under two or more correlated receiver operating characteristic curves: a nonparametric approach. Biometrics. 1988;44(3):837-845.

33. Altenburg WA, de Greef MH, ten Hacken NH, Wempe JB. A better response in exercise capacity after pulmonary rehabilitation in more severe COPD patients. Respir Med. 2012;106(5):694-700.

34. Maddocks M, Kon SS, Canavan JL, et al. Physical frailty and pulmonary rehabilitation in COPD: a prospective cohort study. Thorax. 2016; 71(11):988-995.

35. Hurst JR, Vestbo J, Anzueto A, et al. Evaluation of COPD Longitudinally to Identify Predictive Surrogate Endpoints (ECLIPSE) Investigators. Susceptibility to exacerbation in chronic obstructive pulmonary disease. N Engl J Med. 2010;363(12):1128-1138.

36. Harrison SL, Goldstein R, Desveaux L, Tulloch V, Brooks D. Optimizing nonpharmacological management following an acute exacerbation of chronic obstructive pulmonary disease. Int J Chron Obstruct Pulmon Dis. 2014;9:1197-1205.

37. Man WD, Puhan MA, Harrison SL, Jordan RE, Quint JK, Singh SJ. Pulmonary rehabilitation and severe exacerbations of COPD: solution or white elephant? ERJ Open Res. 2015;1(2):1-10.
International Journal of COPD

\section{Publish your work in this journal}

The International Journal of COPD is an international, peer-reviewed journal of therapeutics and pharmacology focusing on concise rapid reporting of clinical studies and reviews in COPD. Special focus is given to the pathophysiological processes underlying the disease, intervention programs, patient focused education, and self management protocols.

\section{Dovepress}

This journal is indexed on PubMed Central, MedLine and CAS. The manuscript management system is completely online and includes a very quick and fair peer-review system, which is all easy to use. Visit $\mathrm{http}: / / \mathrm{www}$.dovepress.com/testimonials.php to read real quotes from published authors. 